\title{
Benjamín Franklin, España y la diplomacia de una armónica
}

\author{
Celia López Chávez *
}

RESUMEN

En el marco de las relaciones diplomáticas europeas

y norteamericanas en la segunda mitad del siglo xvIII, el objetivo de este estudio es analizar la relación diplomática y personal de Benjamín

Franklin con España y un miembro de la familia real española: el Infante Don Gabriel de Borbón, hijo de Carlos III. Esta relación se inició y desarrolló por el interés que el Infante tenia por

la armónica de vasos, instrumento musical inventado por Franklin. Para este estudio se consultaron documentos de los archivos de Simancas y del Palacio Real de Madrid. El artículo es un avance de un libro que está en preparación titulado "Franklin y España».

\section{ABSTRACT}

Within the context of North American and European diplomatic relations in the second half of the 18th century, the objective of this study is to analize Benjamin Franklin's diplomatic and personal relationship with Spain and a member of the Spanish royal family: the Infante Don Gabriel de Borbón, son of Charles III. This relationship was initiated and developed because of the interest the Infante had toward the glass armonica, which was invented by Franklin. Documents from Archives in Simancas and Palacio Real de Madrid were consulted for this research. The article is an advance chapter of a book in preparation titled "Franklin and Spain».

El 21 de diciembre de 1777 Benjamin Franklin arribaba a París con una misión que cambiaría para siempre el curso de la historia de su futuro país 
y afectaría en gran medida a las relaciones diplomáticas en Europa. Junto a Arthur Lee (quien ya se encontraba en Francia) y Silas Deane (quien desde Londres se dirigió a París), Franklin había sido nombrado comisionado a la Corte de Francia por el Congreso de las recientemente independizadas colonias inglesas de América. La misión consistía en asegurar tratados de comercio y alianza, así como ayuda financiera y militar para la guerra de la independencia de las colonias norteamericanas. Dichos objetivos no sólo incluían a Francia como el más seguro aliado sino también a España. Por esta razón, Franklin llevaba consigo un preciado documento: su nombramiento como Ministro Plenipotenciario ante la Corte de Madrid ${ }^{1 .}$

El viaje de Franklin a España como representante oficial del Congreso de los futuros Estados Unidos nunca se concretó. En París fue convencido por el Conde de Aranda para que no se dirigiera a Madrid, ya que España oficialmente se mantenía todavía neutral sin haber declarado la guerra a Inglaterra (aun cuando ya había comenzado a enviar secretamente ayuda a las colonias, debían tomarse precauciones). Franklin presentó entonces sus credenciales a Aranda en París y el embajador español las envió a Madrid ${ }^{2}$. Sin embargo, el objetivo de su misión en España se hizo efectivo a través de las gestiones diplomáticas con el Conde de Aranda, que culminarian con la entrada de España en la guerra de la independencia de las colonias inglesas el 21 de junio de $1779^{3}$.

Pero la vinculación directa de Franklin con España se había iniciado tres años antes, mediante sus contactos entre 1774 y 1775 con la embajada española en Londres y, como resultado de ellos, a través de la correspondencia mantenida con el hijo de Carlos III, el Infante don Gabriel de Borbón. El presente estudio pretende analizar en detalle dichos antecedentes, que

ARCHIVO HISTÓRICO NACIONAL (en adelante AHN), Estado, legajo 3884, num.20, Aranda a Floridablanca, París, 13 de abril de 1777. En el mismo legajo, num.23, Benjamin Franklin a Aranda, 7 de abril de 1777 (en inglés). Una copia de la carta de Aranda a Floridablanca se encuentra en ARCHIVO GENERAL DE SIMANCAS (en adelante AGS), libro 162, folio $170 \mathrm{rev}$. a 174. El Conde de Aranda era entonces embajador de España en Francia y fue quien (siguiendo instrucciones desde Madrid del Marqués de Grimaldi y del Conde de Floridablanca) se encargó en París de todas las gestiones diplomáticas que incluyeron a España en la guerra de la independencia de los Estados Unidos de América. La designación de Franklin como Ministro Plenipotenciario ante la corte de Madrid fue firmada por John Hancock, presidente del Congreso Americano, con fecha 2 de enero de 1777; el original de este certificado se encuentra en el Archivo Histórico Nacional. Más detalles sobre la localización de este documento y una descripción del mismo se encuentran en: Thomas E. Chávez, An Ultimate Gift. Mariuscrito.

2 T. CHÁvez: An Ultimate Gift, op. cit., p. 123.

3 El tema de los contactos de Franklin con diplomáticos españoles en París y anteriormente en Londres, así como otra documentación relativa a Franklin depositada en los archivos españoles, es objeto de análisis en un libro que está en preparación, del cual el presente artículo constituye una parte: Thomas E. Chávez y Celia López Chávez, Benjamin Franklin and Spain. 
incluyen tanto la vida de los dos personajes centrales de esta historia (Franklin y el Infante don Gabriel), como el contexto en el que se inició el vínculo entre ambos. En dicho marco, el tercer protagonista es un instrumento musical: una armónica de vidrio o también llamada armónica de vasos, instrumento fascinante y popular en Europa en la segunda mitad del siglo XVIII, pero raro, curioso y a la vez intrigante a los ojos de los que viven en las postrimerías del siglo $\mathrm{xx}$.

Como la historia no sólo se hace de grandes batallas y heroicos sucesos, ni sólo de hechos políticos, el presente estudio pretende mostrar cómo la historia política y la diplomacia se pueden mezclar con historias personales. La aparentemente fría correspondencia diplomática puede ofrecernos también un lado humano y cálido en el que se entrelazan, como en este caso, la lucha por la independencia de un país americano y las relaciones diplomáticas en Europa con hechos tan particulares y curiosos como el invento de un instrumento musical y el deseo urgente de un miembro de la realeza europea por poseerlo y aprender a tocarlo.

Los dos hombres de esta historia pertenecieron a generaciones diferentes; crecieron y fueron educados en dos culturas y lenguas diferentes. Franklin, que nació en 1706, tenía 46 años cuando nació don Gabriel en 1752. Mientras el último, hijo de un monarca, dedicaría su vida a las artes y letras y disfrutaría de todos los beneficios de ser descendiente de un rey, el otro, dedicado desde joven a la política, a las ciencias y a las letras, se convertiría en su madurez en enemigo acérrimo de la monarquía por defender los intereses de su futuro país. Sin embargo, el interés por diferentes campos del saber, la curiosidad y el gusto por el arte, en particular la música, uniría a estas dos figuras aunque nunca llegaran a conocerse en persona.

El contacto indirecto entre los protagonistas de esta historia (a través de la embajada española en Londres) se produjo en 1774, cuando Benjamin Franklin se encontraba en Inglaterra. Esta era su tercera visita a este país y la más larga ${ }^{4}$. En la segunda de estas estancias, entre 1757 y 1762 ,

\footnotetext{
4 Nacido en Boston el 17 de enero de 1706, Benjamin Franklin aprendió a los doce años, de su hermano James, el oficio de impresor. A los dieciocho años viajó por primera vez desde Filadelfia a Londres, donde trabajó como impresor. Dos años después (en 1726) volvió a Filadelfia, donde continuó como impresor y comenzó a publicar sus propios escritos. Para la época de su segundo viaje a Inglaterra, en 1757, Franklin había ya ocupado en la administración de Filadelfia diversos cargos tales como: Administrador de Correos, Miembro del Consejo Común y de la Asamblea de Filadelfia, Concejal de Filadelfia y Director General Suplente de Correos de Norteamérica, entre otros. En 1757 fue nombrado Agente de la Asamblea de Pensilvania para tratar negocios en Inglaterra. E propósito de este viaje era negociar (como representante de la Asamblea) con los propietarios de Pensilvania, Thomas y Richard Penn, y con miembros del gobierno británico, para llegar a un acuerdo acerca de las disputas con los propietarios sobre los impuestos a las propiedades.
} 
había recibido una serie de reconocimientos oficiales por su trayectoria intelectual e inventora ${ }^{5}$. Además de sus escritos sobre economía y política, para esta época ya algunos de sus inventos, especialmente los de electricidad, habían llegado a tener notoriedad ${ }^{6}$. Un año antes de su partida de Londres, Franklin conoció la peculiaridad de un instrumento musical que llegaría a marcar aún más su carrera inventora y lo incluiria desde entonces en los anales de la historia de la música.

Fue en la primavera de 1761, antes de su viaje a los Países Bajos ?, cuando Franklin escuchó por primera vez tocar los vasos musicales a Edmund Delaval, también miembro de la Royal Society ${ }^{8}$. La invención de extraer melodias tocando con una varilla los bordes de vasos que contenian agua a diferentes niveles, provenía aproximadamente del siglo Xil, pero fue a principios del siglo XVIII cuando se comenzó a practicar de una forma más seria en conciertos ${ }^{9}$. La técnica fue refinada por el irlandés Richard Pockrich (o Puckeridge), usando las yemas de los dedos en lugar de la varilla. Este músico colocaba vasos de diferentes tamaños en una mesa, uno cerca de otro, y afinaba los tonos poniendo en ellos diferentes niveles de agua; la melodía se creaba al pasar los dedos alrededor de los bordes de los vasos. Pockrich tocó el instrumento por primera vez en Dublín en 1743 y un año después en Inglaterra ${ }^{10}$. No se sabe con certeza si Franklin sabía que los vasos musicales (Glasspiel en alemán) ya eran bastante conocidos en Alemania y que Gluck los había tocado con acompañamiento de orquesta en Londres en $1746^{11}$. De cualquier forma, hacia 1750 los vasos musicales ya habían adquirido cierta popularidad en Europa ${ }^{12}$.

Después de que Franklin escuchara tocar los vasos por primera vez en 1761, quedó tan impresionado que comenzó a trabajar en la aplicación mecánica del principio usado hasta ese momento. Llevado como siempre por esa curiosidad natural que lo había inclinado a inventar, no por beneficios

\footnotetext{
5 Recibió títuios honorarios por las universidades de St. Andrews y Oxford y fue nombrado miembro del Consejo de la Royal Society, en la que sirvió nuevamente en 1765, 1766 y 1772.

6 Entre 1751 y 1754 se publicaron en Londres las tres parte de sus Experiments and Observations on Electricity.

7 En agosto y septiembre de 1761 Franklin viajó con su hijo William a Flandes y Holanda, regresando a Londres para estar presente en la procesión de coronación del rey Jorge III, el 22 de septiembre del mismo año.

8 B. FrANKLIN: The Autobiography and Other Writings. New York, 1961, p. 244; y S. SADIE: The New GROVE Dictionary of Musical Instruments. New York, 1984, 2, p. 725.

9 S. SADIE: The New GROVE Dictionary, op. cit., 2, p. 725.

10 C. Van Doren: Benjamin Franklin, New York, 1980, pp. 299-300; S. Sadie: The New GROVE Dictionary, op. cit., 2, p. 725; y B. FRANKLIN: The Autobiography, op. cit., p. 244.

11 C. VAN DOREN: Benjamin Franklin, New York, 1980, p. 300.

12 S. SADIE: The New GROVE Dictionary, op. cit., 2, p. 725.
} 
económicos sino casi por el afán de divertirse, la invención de la armónica se convertiría en un ejemplo más de esa pasión ${ }^{13}$. Así, hacia el otoño de 1761 Franklin tenía listo un nuevo instrumento basado en la idea de los vasos musicales. En lugar de usar vasos sobre una mesa, Franklin usó vasos especiales fabricados en forma semiesférica, con un agujero en el medio, el más grande de $23,76 \mathrm{~cm}$ de diámetro (nueve pulgadas) y el más pequeño de $7,92 \mathrm{~cm}$ (tres pulgadas). De ellos eligió treinta y siete, según él suficientes para tres octavas con todos los semitonos. Colocó los vasos o copas acomodándolos concéntricamente (el más grande a la izquierda), sujetos en el centro por una varilla de acero dispuesta transversalmente en una caja larga de madera de cuatro patas, similar a un clavicordio. La varilla era accionada por una manivela adherida a un pedal. El músico se sentaba frente al instrumento y hacía girar la varilla con el pedal, similar al de un torno de hilar. Aplicando los dedos a los bordes de las copas, se producía el sonido que variaba de intensidad de acuerdo a la presión ejercida por los dedos. Los vasos se humedecían de vez en cuando con una esponja y agua limpia y los dedos debían mojarse con agua antes de empezar a tocar, sin tener en ellos ningún tipo de suciedad o grasa. El instrumento se afinaba tocándolo repetidamente, si era posible cerca de un bien afinado clavicordio ${ }^{14}$. En una posterior mejora de la armónica los bordes de las copas (al menos hasta la mitad de la longitud de la varilla o huso de acero) eran humedecidos automáticamente por medio de un canal no muy profundo de agua por el cual las copas pasaban al dar vuelta la varilla. No se sabe exactamente a quién se debió esta innovación ${ }^{15}$.

En su carta al científico italiano Giambattista Beccaria, Franklin se refería a su armónica de esta forma: "Es un instrumento que parece peculiarmente adaptado a la música italiana, especialmente aquella de tipo suave y lastimero", y concluía:

"Las ventajas de este instrumento son, que sus melodias son incomparablemente dulces más que ninguna otra; que pueden ser aumentadas o

13 N. Huang: Benjamin Franklin in American thought and Culture, 1790-1990. Philadelphia, 1994 pp. 140-141. Por otra parte, la armónica de vasos no sería su única creación en música, ya que Franklin también compuso música para cuarteto de cuerdas (para tres violines y violoncello, o dos violines, viola y violoncello); la partitura ha sido publicada en: Benjamin Franklin String Quartet, sin paginar.

14 La descripción del instrumento y cómo tocarlo fue explicada por Franklin en una carta al científico italiano Giambattista Beccaria, con quien mantenía correspondencia regular y quien había hecho conocer en Italia muchos de los inventos electrónicos de FRANKLIN: «B. Franklin to Giambattista Beccaria, London, July 13, 1762 ", citada en B. FrANKLIN: The Autobiography, op. cit., pp. 243-247. También véase: C. VAN DOREN: Benjamin Franklin, op. cit., p. 300, y S. SADIE: The New GROVE Dictionary, op. cit., 2, p. 726.

15 S. SAdie: The New GROVE Dictionary, op. cit., 2, p. 726. 
suavizadas como se desee presionando con el dedo en forma más fuerte o más débil y continuada en cualquier duración; y que el instrumento, siendo una vez bien afinado, nunca más necesita afinarse... En honor a vuestra lengua musical, he tomado de él el nombre del instrumento, liamándolo Armónica» ${ }^{16}$.

El constructor de la primera armónica para Franklin fue un hombre llamado Charles James, de Londres, quien fabricó otras copias del instrumento bajo la directa supervisión y especificaciones de Franklin ${ }^{17}$. El instrumento costaba 40 guineas o monedas de oro ${ }^{18}$.

Cuando en noviembre de 1762 Franklin estaba de regreso en Filadelfia ${ }^{19}$, su instrumento musical ya comenzaba a ser tocado en conciertos públicos en Europa. La concertista Marianne Davies, quien se cree que recibió su propia armónica de Franklin, dio conciertos en Inglaterra en 1762 y viajó con el instrumento a Italia, presentándolo también en la corte imperial de Viena (donde Gluck, músico familiarizado con los vasos musicales, era maestro de capilla) y convirtiendo a María Antonieta en una de sus pupilas ${ }^{20}$. Tanto Marianne como su hermana Cecilia Davies (cantante) se habían convertido en las protegidas de Franklin ${ }^{21}$ y en fervientes admiradoras de su invención musical ${ }^{22}$. Marianne tocó la

16 «Franklin to Giambattista Beccaria...»en B. FrankLIN: The Autobiography, op. cit., p. 243. En su descripción del instrumento, Franklin llegaba a ser muy preciso en explicar cada mínimo detalle. Por ejemplo, decía: "Para distinguir los vasos fácilmente, he pintado las partes visibles de los vasos en los lados, cada semitono blanco, y las otras notas de la octava con los siete colores pris. máticos, $C$, rojo; D, naranja; $E$, amarillo; $F$, verde; $G$, azul; $A$, índigo; $B$, púrpura; y $C$, rojo otra vez; así los vasos del mismo color (con excepción del blanco) son siempre octavas a cada uno" (B. Franklin: The Auyobiography, op. cit., p. 247).

17 El nombre del constructor Charles James apareció en el Oxford Journal, el 29 de mayo de 1762; citado en: S. SADIE: The New GROVE Dictionary, op. cit., 2, p. 726.

18 C. VAN DOREN: Benjamin Franklin..., 301.

19 FrANKLIN permaneció en Filadelfia entre noviembre de 1762 y noviembre de 1764. Durante este tiempo continuó en su puesto de Correos en Nueva Jersey, Nueva York y Nueva Inglaterra. Fue testigo y mediador en la masacie de indios en diciembre de 1763 en Pensilvania e insistió a través de sus escritos publicados en la prensa sobre la urgente necesidad de que el rey asumiera el gobierno de Pensilvania indemnizando a sus propietarios.

20 C. VAN DOREN: Benjamin Franklin, op. cit., p. 301.

21 T. FLEMING: The Founding Fathers, op. cit., p. 173.

22. La relación de amistad de Franklin y las hermanas Davies fue usada hasta en ficción. El 19 de marzo de 1873 el New York Evening Mail publicó un articulo basado en la traducción de una novela alemana en la que se mencionaba el origen de la armónica de vasos. Según esta historia, cuando Franklin vivía en Inglaterra visitaba con frecuencia a una viuda liamada Mrs. Davies, quien tenia dos hijas, Mary y Cecilia, que eran admiradoras apasionadas de él. A Cecilia le gustaba cantar para Franklin. Un día Franklin supo que Cecilia había perdido la voz y se quedó tan preocupado que invertó la armónica con la esperanza de que el nuevo instrumento sonara tan maravillosamente como la voz de la joven, por quien tenia un gran afecto. Citado en: N. HuANG: Benjamin Franklin, op. cit., p. 141. 
armónica y Cecilia cantó en la boda de la Archiduquesa Amalia con el Duque Fernando de Parma ${ }^{23}$.

En 1764 la armónica empezó a ser conocida en las colonias norteamericanas y fue escuchada por primera vez en público en Filadelfia en la Sala de la Asamblea en Lodge Alley ${ }^{24}$. Fue en ese mismo año cuando Franklin partió de Filadelfia rumbo a Londres otra vez, permaneciendo en Inglaterra desde diciembre de 1764 hasta marzo de $1775^{25}$. En estos años aumentó aún más la tensión entre las colonias y la metrópoli y Franklin se convirtió en el líder de los intereses coloniales en contra de la Corona inglesa.

En 1773, debido a la popularidad que comenzó a adquirir la armónica de vasos, la familia Mozart (que había conocido a Ms. Davis) mostró interés por poseer dicho instrumento. Así lo manifestaba Leopold Mozart (padre de Wolfgang Amadeus) en una carta a su esposa ${ }^{26}$. Wolfgang Amadeus Mozart compuso música para armónica de vasos en $1791{ }^{27}$. Beethoven y otros músicos de la segunda mitad del siglo xvIII y principios del siglo XIX también compusieron música para este instrumento ${ }^{28}$. Su fama fue aún más estimulada por el uso que el médico austríaco Frank Friedrich Anton Mesmer (1734-1815) le dio al instrumento. Mesmer (quien también conoció a Ms. Davies) aprendió a tocar la armónica y la utilizaba en sesiones de hipnotismo con sus pacientes ${ }^{29}$.

23 T. FLEMING: The Founding Fathers. New York, 1972, p. 173, y J. Sparks: The Works of Benjamin Franklin. Boston, 1840, I, 265; citado en: C. Van Doren: Benjamin Franklin, op. cit., p. 301.

24 C. VAN DOREN: Benjamin Franklin, op. cit, p. 301.

25 En octubre de 1763, después de haber sido derrotado en su reelección a la Asamblea por Filadelfia, fue elegido como agente para ir otra vez a Inglaterra. El propósito de esta misión era persuadir al gobierno británico de que suprimiese el gobierno de propietarios de Pensilvania y de que la Corona asumiera el control directo. Durante su estancia en Inglaterra fue nombrado también agente por Georgia (1768), Nueva Jersey (1769) y Massachusetts (1770)

26 S. SADIE: The New GROVE Dictionary, op. cit., 2, p. 726, y R. Darrell: Music for Glass Harmonica. New Jersey, 1987, CD Rom (portada).

27 Mozart compuso especialmente para el concierto dado por Marianne Kirchgessner (sucesora de Marianne Davies), el Adagio y Rondo en C menor, K.617 y el Adagio en C mayor. El Adagio y Rondo fueron compuestos para ser interpretados con armónica, flauta, oboe, viola y violoncello; citado en $\mathrm{S}$. SADIE: The New GROVE Dictionary, op. cit., 2, p. 726 y R. DarRell, Music..., CD Rom (portada).

28 S. SADIE: The New GROVE Dictionary, op. cit., 2, p. 726; C. VAN DOREN: Benjamin Franklin, op. cit., p. 301; T. Fleming: The Founding Fathers, op. cit., p. 173 y R. Darrell: Music..., CD Rom (portada). Ludwig van Beethoven compuso en 1815 la música de escena para el drama "Leonore Prohaska», que incluia música de armónica de vasos. Otros compositores de música para armónica de vasos fueron: Johann Friedrich Reichardt (1752-1814), Karl Leopold Rölling (1735-1804). Johann Abraham Peter Schultz (1747-1800) y Johann Gottlieb Naumann (1741-1801); véase: $H$ Klein: «Leonore Prohaska», Beethoven..., (CD Rom).

29 S. SADiE: The New GROVE Dictionary, op. cit., 2, p. 726. Anton Mesmer publicó en 1775 su estudio sobre el magnetismo animal demostrando cómo se podía curar pacientes con un tipo de hipnotismo (su método es llamado también "mesmerismo"). 
Evidentemente en la década de 1770 este instrumento musical era ya popular no sólo en las cortes europeas, sino entre científicos y músicos de renombre. Un año después de que los Mozart quisieran adquirir una armónica de vasos, Franklin recibiría una especial petición desde España. Uno de los hijos del rey Carlos III también quería tener una.

El Infante don Gabriel de Borbón era el décimo de los trece hijos de Carlos III y su esposa María Amalia de Sajonia ${ }^{30}$. El rey nunca ocultó su preferencia por el Infante don Gabriel y posteriormente por la que sería su esposa en 1785, la Infanta María Ana Victoria, hija de los reyes de Portugal. La predilección del rey por ellos provocó situaciones de conflicto en la familia real por las rivalidades suscitadas ${ }^{31}$. En 1774 el Infante contaba con veintidós años de edad y para esta época ya había mostrado su gran afición por las artes y las letras. Su educación había estado a cargo del Duque de Béjar. En comparación con sus otros dos hermanos, Fernando (rey de Nápoles y Sicilia) y Carlos (sucesor al trono de España), don Gabriel vivió completamente alejado de la política, dedicado a desarrollar sus dotes intelectuales y artísticas. Tocaba el clave y solía interpretar con maestría piezas difíciles. Se aficionó al estudio de los clásicos y la lengua latina ${ }^{32}$. Como resultado de su interés por difundir la Historia Antigua, tradujo al castellano las obras del escritor romano Cayo Salustio La Conjuración de Catilina y la Guerra de Jugurta que fueron publicadas en el año 1772. En el prólogo de su libro el infante decía: «Mi intento en esta traducción es que puedan los españoles, sin el socorro de la lengua latina, leer y entender sin tropiezo las obras de Cayo Salustio Crispo... Y ojalá que con esto abriera yo camino a nuestros escritores..." ${ }^{33}$.

Según su biógrafo, don Gabriel era un producto indiscutible de la llustración y prueba de ello fueron sus diferentes aficiones: desde la literatura y el

30 El matrimonio tuvo primero cinco hijas; tres de ellas fallecieron siendo muy niñas. Luego vino el primer varón llamado Felipe Pascual, quien por razones de salud mental y física no llegó a ser sucesor. 디 segundo hijo varón (y séptimo en número) fue Carlos, que sería el sucesor al trono de España. El tercer hijo varón, Fernando, fue el sucesor al trono de Nápoles. Entre Carlos y Fernando nació otra hija (María Teresa), que murió al poco tiempo de nacer. Gabriel fue el siguiente hijo varón, después de Fernando, y nació el 11 de mayo de 1752. Después de Gabriel el matrimonio tuvo otra niña (María Ana), que falleció al poco tiempo, y dos varones más (Antonio y Francisco Javier). El Infante Don Gabriel vivió junto con el resto de la familia real en Nápoles (donde su padre, Carlos VI, era rey) hasta 1759, cuando su padre asumió el trono de España como Carlos III.

31 M. Pérez Samper: La vida y época de Carlos III. Barcelona, 1998, p. 278.

32 Para detalles sobre la vida y aficiones del Infante don Gabriel véase: Juan Martínez CuEsTA: "Relaciones culturales entre ia corte de Carlos III y los Estados Unidos de América", Madrid en el contexto de lo hispano desde la época de los descubrimientos. Madrid, 1994, II, pp. 1063-1070. Martínez Cuesta es autor de una biografía (sin publicar) del Infarite don Gabriel de Borbón.

33 j. Martinez Cuesta: “Relaciones culturales...", op. cit., p. 1067. 
estudio de la lengua latina, a la música, la pintura y las máquinas, especialmente los globos aerostáticos ${ }^{34}$. Llevado por su espíritu ilustrado llegó a convertirse en pintor, constructor de globos, escritor y músico. Fue su apasionado interés por la música lo que llevó a don Gabriel a querer aprender a tocar aquel instrumento musical tan popular en la segunda mitad del siglo XVIII en Europa: la armónica de vasos. La introducción de este instrumento en España coincidía con el predicamento que estaba adquiriendo en general en Europa, aunque varios años después de que fuera conocido en las colonias norteamericanas. En abril de 1771 don Gabriel escuchó por primera vez tocar dicho instrumento, en un concierto a cargo de Ignacio Schmidt. En febrero de 1772 el infante compró el instrumento al propio Schmidt junto con papeles de música compuesta especialmente para armónica ${ }^{35}$.

El interés de don Gabriel por el instrumento y quizás el deterioro del que habia comprado dos años antes, fueron las razones que lo llevaron a querer adquirir uno en Londres en 1774. La embajada española en Londres se encargaría de la gestión. El Príncipe de Masserano, embajador español en Inglaterra pero que en 1774 se encontraba en Madrid recuperándose de problemas de salud ${ }^{36}$, se comunicó inmediatamente con Francisco Escarano (secretario de la embajada) para que le consiguiera la armónica de vasos para el infante, entre enero y abril de 1774 Francisco Escarano hizo en Londres los arreglos necesarios para adquirir el instrumento.

Al recibir la orden, Escarano se dirigió a la famosa concertista de armónica Marianne Davies ${ }^{37}$, diciéndole que deseaba adquirir una armónica para una hermana suya, a lo que Davies respondió que la armónica que tenía en Londres era la que ella usaba y que tenía otra en Florencia, a donde pensaba volver pronto, pero que no quería deshacerse de ninguna de ellas ${ }^{38}$. Al no obtener resultado y conociendo sin duda la vinculación de Franklin con el instrumento, Escarano se dirigió a él. En su carta al Príncipe de Masserano decía, refiriéndose a este primer encuentro con Franklin:

\footnotetext{
34 J. Martínez Cuesta: Relaciones culturales..., op. cit., p. 1064.

35 J. MARTINEZ Cuesta: Relaciones culturales..., op. cit., p. 1066.

36 J. Yela UtRILla, España. ante la Independencia de los Estados Unidos. Madrid, 1988, p. 42. Ver notas $20,21,22$ y 23.

38 AGS, Estado, 7016, Escarano a Masserano, Londres, 13 de enero de 1774. En su carta al Príncipe de Masserano, Escarano decia al referirse a su encuentro con la señorita Davies: "Me añadió que su padre, que era el inventor, acababa de morir, y que no encontraría ciertamente en Inglaterra quien me hiciese uno igual. Hicele mil promesas porque me cediese el que tenia en Londres, y no huvo forma de consentir en ello". Es importante notar la mención en esta carta del padre de Marianne Davies como el inventor del instrumento. La bibliografía consultada para este estudio no menciona esta conexión entre el padre de Davies y el instrumento musical.
} 
"Oí que el famoso Doctor Franklin, a quien VE conoce, tenía uno: fuí a verle, y le manifesté mis deseos de que me lo cediese: Este Philosopho, que es el mejor hombre del mundo, me confesó tener dos instrumentos de los que yo quería; el uno en America, para donde va a partir en breve, y el otro en Londres: Me dijo, assimismo que gustoso me renunciaria el que tenia en su poder si no tuviese quatro, o cinco vasos rotos, y si fuese perfecto; que el componerle era cosa muy difícil, y que assi lo unico que podia hacer era sugerirme un hombre, que en otro tiempo solia trabajar tales instrumentos, pero que me prevenia me pediria más de cincuenta Libras sterlinas en caso de determinarse a hacerle. Le di mil gracias por su consejo, y al despedirme le saqué casi la palabra de que si el referido hombre no consentia en hacerme la armonica me cederia la suya por lo que le avia costado" ${ }^{39}$.

La gestión con el constructor del instrumento también resultó infructuosa ${ }^{40}$, lo que llevó a Escarano a entrevistarse nuevamente con Franklin, quien finalmente accedió a darle su armónica por lo que le habia costado, pero haciéndola reparar antes. En la misma carta donde Escarano cuenta este episodio, se refiere a Franklin de esta forma:

"Como a los hombres de bien no debe hacerseles misterio le confesé que se trataba de complacer al Sr. Infante, lo que le ha empeñado más a darme bien compuesto su instrumento, lo que no podrá ser antes de un mes" ${ }^{41}$.

En este su segundo encuentro con Franklin, Francisco Escarano le solicitó una explicación sobre el modo de tocar el instrumento. A lo que Franklin respondió diciéndole que en sus Obras traducidas e impresas en francés se hallaba una carta suya a Giambattista Beccaria ${ }^{42}$ en la que se detallaba el modo de tocar ${ }^{43}$.

39 AGS, Estado, 7016, Escarano a Masserano, Londres, 13 de enero de 1774.

40 AGS, Estado, 7016, Escarano a Masserano, Londres, 1 de febrero de 1774: «... aviendo pasado a casa del obrero que me indicó el famoso Doctor Franklin me mostró con mucha dificultad el Instrumento que tenia como una cosa muy rara, y preguntando si quería vendermele para una hermana mia me respondió que no se deshacia de él por ningún dinero. Fueron inutiles todos mis ruegos para persuadirle a cedermelo, y lo fueron también para reducirle a que me hiciese a otro semejante insistiendo siempre en decirme que ni por cien Guineas te emprenderia. Sabiendo que es casi imposible vencer la obstinacion de un Ingles fui a contar lo que me havia pasado a Mr. Franklín...". La carta no menciona el nombre del constructor del instrumento, pero puede suponerse que quizás se trataba de Charles James (ver nota 17).

4 AGS, Estado, 7016, Escarano a Masserano, Londres, 1 de febrero de 1774.

42 Ver notas 14 y 16 .

43 AGS, Estado, 7016, Escarano a Masseranc, Londres, 1 de tebrero de 1774. En su carta Escarano mencionaba la preocupación de Franklin porque entendiera las instrucciones y decia: «... pero que no obstante si despues de aver examinado tal carta viese que no estaba muy clara me formaria una ciarissima instruccion y me la entregaria. VE vé que el Doctor Franklin no podia aver procedido con más garbo, y que debemos estarle reconocidos". 
Los días en que Escarano gestionaba la adquisición de la armónica no eran para nada favorables en la vida pública de Franklin. En los últimos dos años se había acrecentado la tensión política en Londres y en las colonias, culminando el 16 de diciembre de 1773 con la rebelión del té en Boston y otros sucesos como la masacre acaecida en la misma ciudad. Las noticias de estos hechos fueron publicadas en Londres el 22 de enero de $17744^{44}$. Aparentemente, los actos de rebelión en las colonias agravaron aún más la situación de Franklin con la consecuencia de su destitución como delegado de la Royal Post Office ${ }^{45}$.

En carta con fecha 11 de marzo de 1774 Francisco Escarano le hacia saber al Príncipe de Masserano que finalmente Franklin le había entregado la armónica ya reparada junto con los dos tomos de sus obras traducidas al francés, en cuya página 209 estaba la explicación sobre cómo tocar el instrumento. "He dado al Dr. Franklin las gracias», escribía Escarano, "diciéndole que no dudaba que su Alteza leería con mucho gusto sus obras, y le he pagado el coste del Instrumento, y su compostura,..." ${ }^{46}$. En estos días, por otra parte, las circunstancias en Londres eran mucho más difíciles para Franklin que el hecho de explicar cómo tocar la armónica: «Se empieza a tratar en el Parlamento el arduo asunto de las colonias de América...", decía Escarano en la misma carta ${ }^{47}$. Escarano pagó a Franklin 17 libras esterlinas y 17 chelines por la armónica. La cuenta de gastos dirigida por Escarano al Príncipe de Masserano incluia una recomendación:

“No sé si convendría que el Sr. Infante Don Gabriel correspondiese al regalo de los libros del Doctor Franklin con el suyo. Perdone V.E. este sugerimientos ${ }^{48}$.

Vía Bilbao el instrumento fue enviado a Madrid, aunque no sin retraso ya que para principios de abril todavía el navío que debía transportar la

44 L. Labaree, R. Ketchman, H. Boatfielo y H. Fineman: The Autobiography of Benjamin Franklin. New Haven, 1964, pp. 312-313, y J. Blum, E. Morgan, W. Rose, A. Schlesinger Jr., K. Stampp y C. Van WOODWARD: The National Experience. A History of the United States to 1887. New York, 1973, p. 94.

45 L. LABAREE y otros: The Autobiography, op. cit., p. 313.

46 AGS, Estado, 7016. Escarano a Masserano, Londres, 11 de marzo de 1774.

47 AGS, Estado, 7016. Escarano a Masserano, Londres, 11 de marzo de 1774.

48 AGS, Estado, 7016, Escarano a Masserano, Londres, 18 de marzo de 1774. La suma total era de 20 libras esterlinas (con gastos de embalaje, aduana y transporte). Masserano firmó a continuación de la cuenta enviada por Escarano el recibo del pago hecho por el Infante don Gabriel: «He recibido esta suma del Sr. infante Don Gabriel para quien es el instrumento nombrado la Armonica, en Madrid a 11 de abril de 1774". Otra referencia a la compra del instrumento aparece en el siguiente documento: ARCHIVO GENERAL DE PALACIO (en adelante AGP), Archivo del Infante don Gabriel, legajo 501, Masserano al Duque de Bexar, 6 de abril de 1774: comunica la noticia del envío de la armónica que hace Escarano y de la cuenta con el importe total de 20 libras esterlinas para proceder a su pago. 
armónica no había partido de Londres, lo que impacientaba a Escarano, quien insistía en sus cartas en querer cumplir las órdenes del Infante con todo celo y eficiencia, especialmente por lo ansioso que el hijo del rey estaba por ver dicho instrumento ${ }^{49}$.

Siguiendo la sugerencia de Escarano, el Infante don Gabriel correspondió el favor de Benjamin Franklin y el del propio Escarano con el envío de dos copias de su libro, lo que el secretario de la embajada agradeció de esta forma:

"Suplico a VE (si acaso esta mía le encuentra en Madrid) ponerme a los pies de su Alteza, y rendirle humildes gracias por el libro que se ha dignado regalarme, el que guardaré toda mi vida como el mayor tesoro. No dudo que el Doctor Franklin apreciará tan magnífico regalo: assi él, como yo debemos estar muy reconocidos a VE que es quien nos lo ha facilitado" ${ }^{50}$.

Mientras, en las colonias continuaban los tumultos. Entre marzo y junio de 1774 la situación empeoró al imponer el gobierno británico una serie de leyes que los colonos consideraron coercitivas ${ }^{51}$. La correspondencia del secretario de la embajada española en Londres mostraba esta situación conflictiva. En carta de 15 de julio del mismo año Escarano mencionaba los últimos rumores acerca de los sucesos de Boston:

"Dicen que en Boston hay un partido que inclina a someterse al Govierno, y a dar satisfaccion a la Compañia de Indias por los perjuicios que se le han causado en la destruccion del the, pero que el nuevo Governador General Sage les avia dicho que si querian de veras reconciliarse con esta Corte era menester que convocasen una asamblea general en que resolviesen los actos de sumision que avian de hacer" ${ }^{52}$.

49 AGS, Estado, 7016, Escarano a Masserano, Londres, 18 de marzo de 1774: «El Navio Santo Domingo, y la Buenaventura del capitan Cotarro es el que lleva la armonica, cuyo coste importa veinte libras sterlinas segun verá VE en la adjunta cuenta. Don Luis de Ventades pagará el porte hasta Bilbao, y cuydará de remitirla a Madrid con el mayor cuidado, segun se lo prevengo. Le digo que espere las ordenes de VE o las del Sr. Marques de Grimaldi, y que haga quanto esté de su parte para que este instrumento llegue a la corte lo más presto que sea posible». En carta fechada en 1 de abril Escarano decía: «No ha partido aun el Navio que lleva la Armonica. Ya conoce VE las cosas de Ventades: Ha quince dias que me dijo que iba a hacerse a la vela. Me estoy consumiendo porque conozco que el Sr. Infante estará esperando con ansia el ver dicho instrumento..." (AGS, Estado, 7016, Escarano a Masserano, Londres, 1 de abril de 1774).

50 AGS, Estado, 7016, Escarano a Masserano, Londres, 1 de abril de 1774.

51 L. LABAfEE y otros: The Autobiography, op. cit., p. 313 , y J. BLum y otros: The National Experience, op. cit., p. 94-95. Tales leyes son conocidas en la historia de los Estados Unidos como "The Intolerabie Acts" (Boston Port Act, Massachusetts Government Act y The Quartering Act) y estaban destinadas a establecer un control más estricto sobre las colonias.

52 AGS, Estado, 7016, Escarano a Masserano, Londres, 15 de julio de 1774. 
En el último párrafo de la misma carta Escarano daba en francés noticias de Franklin:

«El Dr. Franklin todavía se encuentra en Londres. Lo he visto hace poco. Siempre habla de su viaje a América, pero como hace más de un año que habla de esto, nos congratulamos de tenerlo aquí todavía por algún tiempo " ${ }^{53}$.

La salida de Franklin de Londres se produjo al año siguiente. Partió muy molesto a Filadelfia el 20 de marzo de 1775. Escarano daba cuenta de su partida en una carta al Marqués de Grimaldi en los siguientes términos:

«El Ministerio ha visto partir de aquí con sumo sentimiento al celebre Doctor Francklin (sic). Resentido como estaba contra este Govierno por haverle quitado un empleo de gran lucro que tenia en Philadelphia, es verosimil haga mucho mal en aquella Provincia en donde le miran como al Padre de la Patria» ${ }^{54}$.

El «mal» al que se refería Escarano era sin duda el protagonismo directo de Franklin en los sucesos que llevaron a la declaración de independencia de las colonias inglesas el 4 de julio de 1776. Inmediatamente después de su llegada a América, en mayo de 1775. Franklin fue elegido delegado al Segundo Congreso Continental y comenzó a trabajar en el borrador de los “Artículos de la Confederación de las Colonias Unidas» ${ }^{55}$.

En medio de tanta agitación en estos meses decisivos, Franklin encontraria tiempo para escribir al Infante don Gabriel. A fines del año 1775, desde Filadelfia, agradeció por carta el libro de las obras traducidas de Salustio que el Infante le hiciera llegar. Franklin se mostraba no sólo agradecido por el libro, sino también esperanzado en que las relaciones entre España y las colonias norteamericanas se afianzaran para defenderse de las otras potencias europeas. El interesante contenido de esta carta merece su traducción y transcripción completas:

Filadelfia, Diciembre 12, 1775

llustrísimo Príncipe!

Acabo de recibir de manos del Embajador de España, el muy estimado presente que su más serena Alteza tan amablemente me ha enviado, de su excelente version de Salustio. Estoy extremadamente conciente del honor que se me ha hecho, y le pido que acepte mi agradecido reconocimiento. Desearía poder enviarle desde aquí alguna producción literaria americana digna de ser

53 AGS, Estado, 7016, Escarano a Masserano, Londres, 15 de julio de 1774

54 AGS, Estado, 7016, Escarano a Grimaldi, Londres, 31 de marzo de 1775.

55 L. LABAREE y otros: The Autobiography, op. cit., p. 314. 
leída; pero todavía las musas apenas han visitado estas remotas regiones. Quizás, de cualquier manera, las últimas actas de nuestro Congreso Americano, recién publicadas, pueden ser tema de cierta curiosidad en su Corte. Por eso me tomo la libertad de enviar a su Alteza una copia, con algunos otros papeles que contienen relatos de los éxitos con los que la Providencia nos ha favorecido últimamente. En eillo sus sabios políticos pueden contemplar los primeros esfuerzos de un Estado naciente, el cual parece que probablemente pronto tomará parte de cierta importancia en el escenario de los Asuntos Humanos, y proporcionará materiales para un futuro Salustio. Estoy muy viejo, y apenas puedo esperar ver el resultado de esta gran contienda; pero mirando hacia adelante pienso que veo un poderoso dominio creciendo aqui, cuyo interés será formar una cercana y firme alianza con España y sus territorios fronterizos a los nuestros; y que estando unidos serán capaces, no sólo de mantener su propia gente en paz, sino rechazar la fuerza de todas las otras potencias en Europa. Por eso parece prudente por los dos lados cultivar un buen entendimiento que puede ser muy útil de aquí en adelante para ambos; hacia el cual una justa base está ya en nuestras mentes por la bien fundada opinión popular abrigada aqui de la integridad y honor españoles. Espero que se perdone mi pretensión al insinuar esto. Si hay cualquier cosa de este lado del Globo que puedo hacer en uno u otro servicio o deleite por suAlteza Real, sus órdenes me harán feliz. Con la más alta estima y veneración, tengo el honor de ser el más obediente y humilde servidor de su serena Alteza.

Benjamin Franklin ${ }^{56}$.

Las palabras de Franklin hacian directa alusión a los hechos que estaban ocurriendo en las colonias americanas y que cambiarían por completo su historia y la de las relaciones diplomáticas con España, nación que, según se desprendía del propio Franklin, estuvo incluida desde el principio en los planes de emancipación de las colonias inglesas. Las palabras de Franklin ya no eran proféticas, sino tan reales como la misma independencia que se declararía siete meses después. Algunas semanas antes de esta proclamación Franklin ya había comenzado a trabajar en un comité junto con John Adams y otros delegados para la preparación de un plan de tratados con potencias extranjeras ( $P$ Plan of 1776"). En octubre de 1776 Franklin partió a Francia con la misión de asegurar tratados de comercio y alianza, así como ayuda financiera y militar. Esta misión, de la que Silas Deane y Arthur Lee también formaron parte, iniciaría inmediatamente los contactos con España buscando una alianza similar a la francesa. La ayuda española (tal como se dijo al comienzo de este estudio) tardó en hacerse oficial porque desde el principio la Corona española se mostró prudente y cautelosa, pero finalmente terminó siendo

56 AGP, Archivo del Infante don Gabriel, Secretaría, legajo 738, Philadelphia, December 12. 1775, Benjamin Franklin to His most serene Highness Don Gabriel of Bourbon. 
de tal magnitud que hoy ya no hay duda entre los investigadores del tema sobre lo decisivo que fue para la independencia de las colonias inglesas el papel de España, sus diplomáticos, sus generales, sus soldados, su equipamiento militar, sus buques y su dinero ${ }^{57}$.

Mientras las negociaciones diplomáticas continuaban y la guerra por la independencia de las colonias norteamericanas se extendía hasta el año 1783, el Infante don Gabriel había aprendido a tocar la armónica de vasos. Su música era escuchada en conciertos dados en el Palacio Real y el infante solía viajar con su instrumento musical a todos los Reales Sitios a donde se desplazaba la Corte ${ }^{58}$. Así, a pesar del cuidado puesto en su transporte, en más de una ocasión los vasos se rompieron y debieron ser repuestos ${ }^{59}$.

Don Gabriel murió el 13 de noviembre de 1788. Se había contagiado de viruelas al no querer separarse de su esposa, doña María Ana, quien habia fallecido a consecuencia de la misma enfermedad once días antes ${ }^{60}$. Después de la muerte de don Gabriel, su colección de instrumentos musicales fue vendida en almoneda pública junto con otros de sus bienes. Parece ser que entre los que quedaron sin comprarse se encontraba la armónica de vasos ${ }^{61}$, aunque actualmente dicho instrumento musical no se conserva en las colecciones reales ${ }^{62}$.

Benjamin Franklin murió en 1790, dos años después de don Gabriel. A diferencia de éste último, que falleció a los 36 años, Franklin vivió 84 años. Tuvo oportunidad de participar activamente en el nacimiento de su nuevo país, con la certeza de que se había cumplido lo que mencionaba en su carta

57 Sobre el tema de la ayuda de España a la guerra de la independencia de los Estados Unidos el estudio más completo en inglés será publicado en un futuro próximo: T. CHAVEZ, An Ultimate Gift... En cuanto a los estudios en castellano, véase: Eric BEERMAN, España y la independencia de los Estados Unidos, Madrid, Editorial Maptre, S.A., 1992; Francisco MORALEs Padrón, Participación de España en la independencia politica de los Estados Unidos, Madrid, Publicaciones Españolas, 1952; Joaquin Oltra y María Ángeles PÉREz SAMPer, El Conde de Aranda y los Estados Unidos, Barcelona, Promociones y Publicaciones Universitarias, 1987; Maria Pilar RuIGOMEZ DE HERNÁNDEz, El gobierno español del Despotismo llustrado ante la independencia de los Estados Unidos de América, Madrid, Ministerio de Asuntos Exteriores, 1978; J. YeLA UTRILLA, España, op. cit.

58 J. Martínez Cuesta, Relaciones culturales..., op. cit., p. 1066.

59 J. Martinez Cuesta, Relaciones culturales..., op. cit., pp. 1066-1067: «... se fabricaban en la Real Fábrica de San Ildefonso. La factura más importante corresponde al mes de agosto de 1778 en que se llegaron a encargar hasta un total de doscientos siete, cantidades que no fueron suficientes, ya que al mes siguiente se solicitaron otros treinta y cuatro, situación que hace pensar en un importante percance durante su traslado de San Ildefonso a San Lorenzo".

60 M. Pérez Samper: La vida, op. cit. pp. 278-279.

61 J. Martinez Cuesta: Relaciones culturales..., op. cit., p. 1067

62 Información proporcionada por el mismo José Martínez Cuesta, del Area de Conservación del Patrimonio Nacional, Palacio Real. 
de 1775 al infante don Gabriel: la alianza de las colonias norteamericanas con España y la consecuente ayuda española en favor de la independencia.

En cuanto a la vida de la armónica de vasos, órgano de vasos o armónica de vidrio, su popularidad se extinguió algunas décadas después de los otros dos protagonistas de esta historia. Hacia el año 1830 la armónica de vasos había perdido importancia. En parte se debió a testimonios que constataban efectos negativos en el sistema nervioso de los músicos que la tocaban; por el continuo contacto de los dedos con los vasos vibrantes. Debido a su sonido extraordinariamente dulce y etéreo, se pensó que tenía efectos depresivos en los músicos, hasta el punto de provocar ataques de nervios ${ }^{63}$. También, en sentido contrario, se llegó a sospechar del efecto por demás tranquilizador que provocaba en la audiencia que escuchaba los conciertos. En algunas ciudades alemanas el uso del instrumento llegó a ser prohibido por la policía.

En el siglo xx la música de la armónica de vasos y de los vasos musicales se revitalizó durante las décadas de 1960 y 1970 gracias al músico alemán Bruno Hoffmann, quien comenzó a usar para este instrumento el nombre de "arpa de vasos" (glass harp) ${ }^{64}$. Actualmente existen alrededor de cien ejemplares nuevos de la armónica de vasos (siguiendo el modelo creado por Franklin) y hay músicos que tocan la armónica en conciertos públicos en Europa y los Estados Unidos. También algunos museos de Europa y Estados Unidos conservan en sus colecciones ejemplares del siglo XVIII de este instrumento tan fascinante y peculiar.

63 T. FlEMING: The Founding Fathers, op. cit., p. 173.

64 S. SADIE: The New GROVE Dictionary, op. cit., 2, p. 726. 


$$
\text { I. } P_{a y} \cdot 18,5
$$

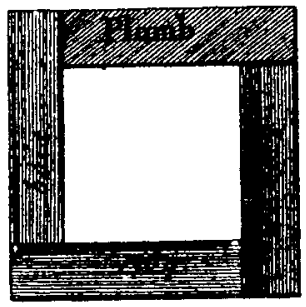

2. $P(9 g \cdot 210$

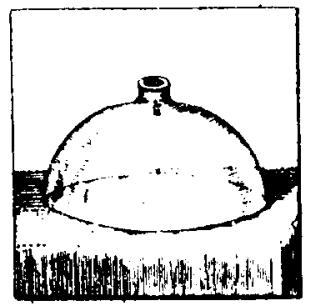

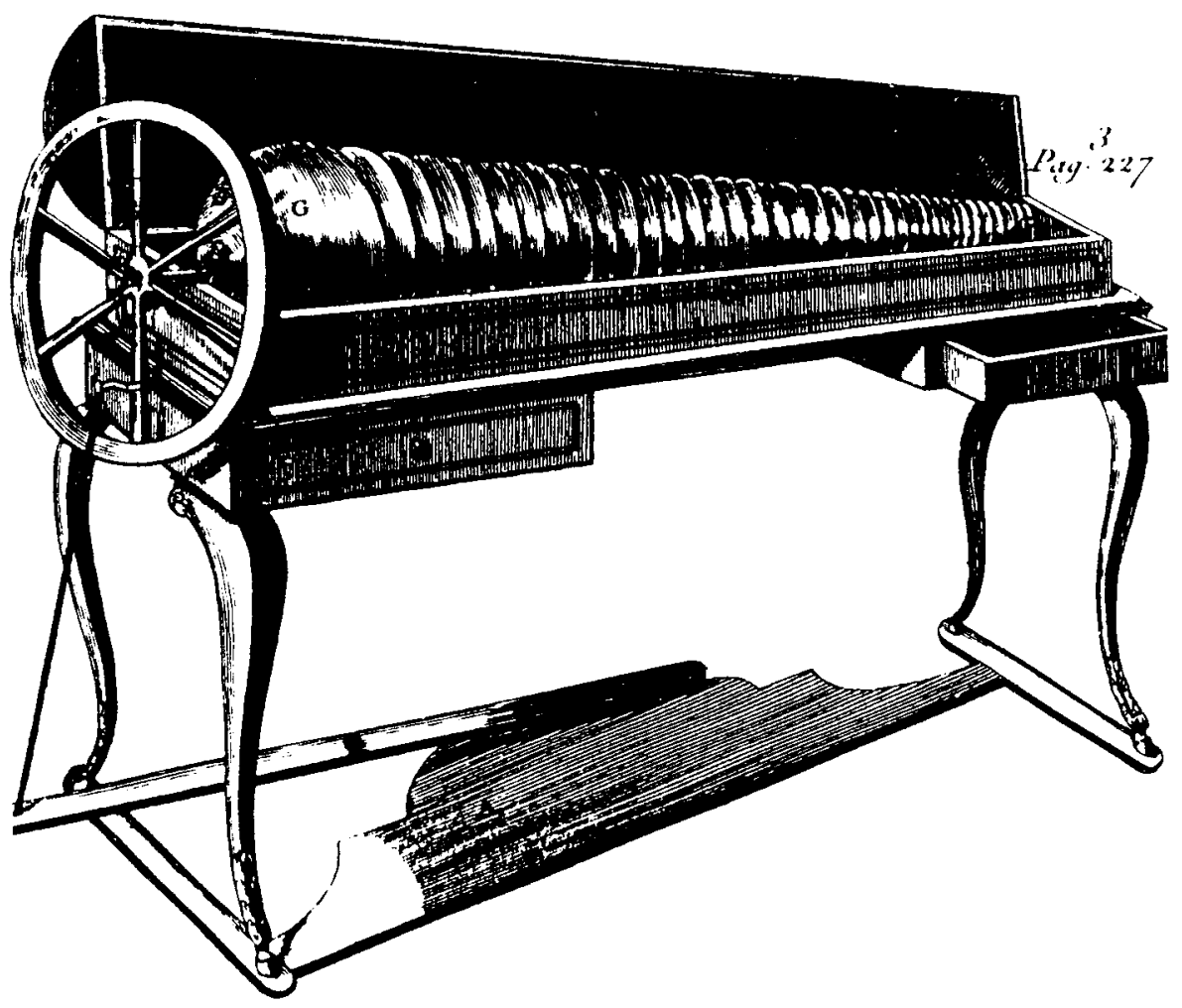




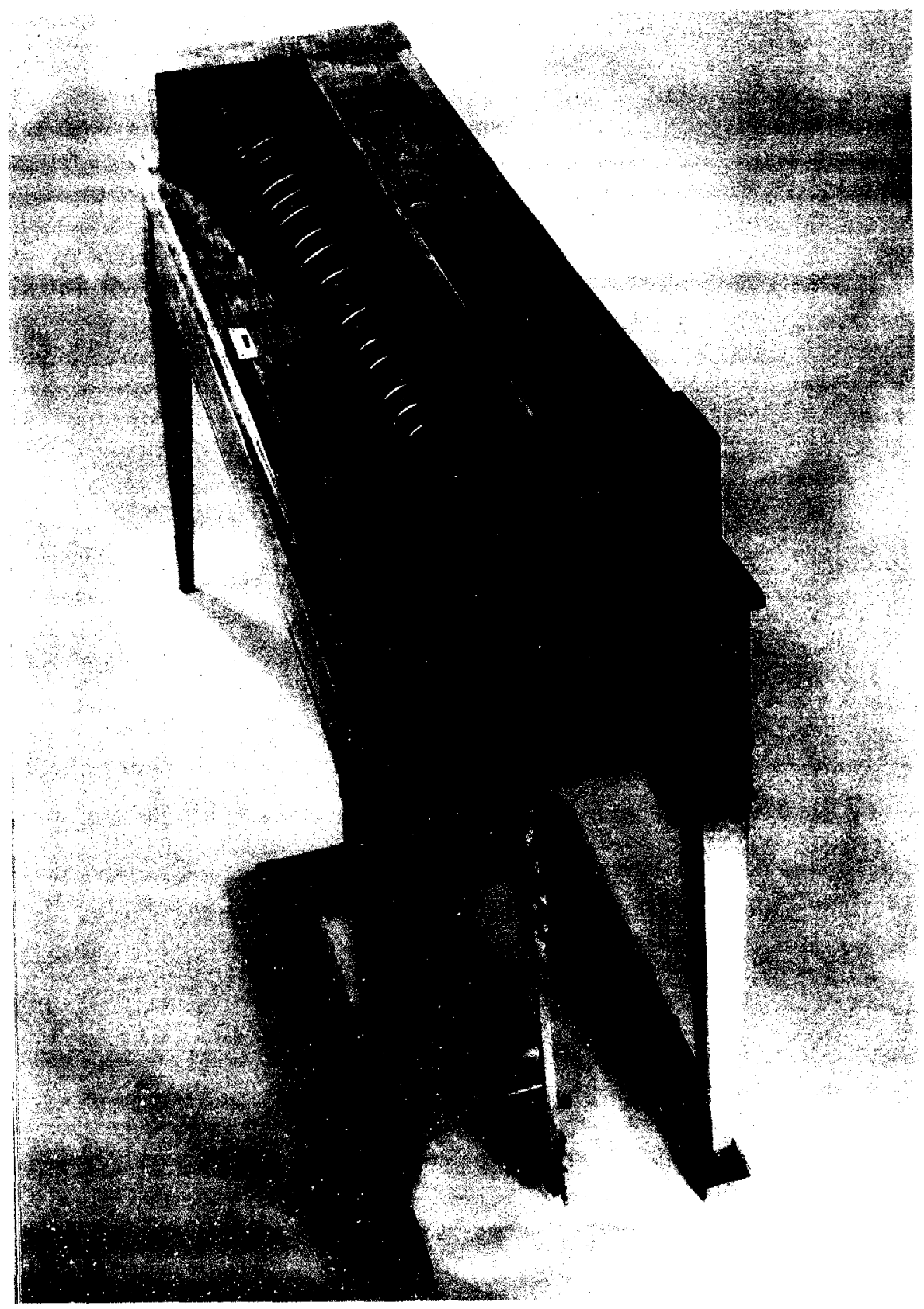

Foto de una armónica de vasos del siglo XVIII, publicada en: Roger Bragard y Férdinand J. Dehen, Musical Instruments in Art and History, New York, The Viking Press, 1968, p. 204. 
Benjamin Franklin, España y la diplomacia de una armónica

\begin{tabular}{|c|c|c|c|c|c|c|c|c|c|c|c|c|c|c|c|}
\hline 200 & 217 & 232 & 249 & 8 & 25 & 40 & $.5 \%$ & $7 ?$ & 89 & 104 & 121 & 136 & 153 & 168 & 185 \\
\hline 58 & 39 & 26 & 7 & 250 & 231 & $2 / 8$ & 199 & 186 & 167 & 154 & 135 & 122 & 10.3 & 90 & 71 \\
\hline 98 & 219 & 230 & 251 & 6 & 24 & 88 & 9 & 70 & 91 & 102 & 123 & 134 & 155 & 166 & 187 \\
\hline 60 & 37 & 28 & 5 & $2 \beta 3$ & $2 p$ & $2 \geq 0$ & 197 & 188 & $16_{5}$ & 156 & 133 & 124 & 101 & 92 & $6 g$ \\
\hline 01 & 216 & 233 & & & & & & 73 & 88 & 105 & 120 & 132 & 152 & 169 & 184 \\
\hline 55 & 42 & & & 347 & 2.34 & $2 \sqrt{5}$ & 262 & 123 & 17o & 151 & 188 & ing & 10,6 & 87 & 74 \\
\hline 203 & 214 & 235 & 246 & 11 & & $A 3$ & & 75 & $8(i)$ & $10 x$ & $1 \times 8$ & 139 & 150 & 171 & \\
\hline & & & & & & $2 \sqrt{3}$ & 204 & 181 & $1>2$ & $i_{\theta}$ & 170 & 117. & 108 & & \\
\hline & & & 2 & & & $A 5$ & 52 & $7 x$ & $3+$ & 109 & $1>Q^{\prime}$ & 171 & 17.9 & & \\
\hline$\pi$ & & & & & 238 & 211 & 206 & 179 & i7t! & $A x$ & $1 \neq 2$ & it 5 & Mo & & \\
\hline & 250 & 259 & $\because A 2$ & ג'5 & 18 & 47 & 50 & 74 & 82 & $>$ & $1 x+4$ & $1+3$ & ix & & \\
\hline & & & 8 & 241 & 240 & 209 & 208 & 177 & 176 & 1.15 & $1+4$ & $1 / 23$ & 172 & 81 & \\
\hline 196 & 351 & 354 & 20.3 & 4 & 29 & 36 & 61 & 88 & ().3 & 100 & $1225 \mid$ & $7: 3: 2$ & 157 & & \\
\hline 62 & 25 & 20 & 9 & 254 & 227 & 222 & 195 & 190 & 163 & 158 & 1,31 & $126^{\circ}$ & 99 & 4 & \\
\hline 184 & 295 & 226 & 255 & 2 & $3 t$ & 34 & 63 & $66^{\circ}$ & 95 & 98 & 127 & 130 & 159 & 102 & Ix \\
\hline$\theta_{4}$ & 33 & 32 & 1 & 256 & 225 & 224 & 193 & 192 & 161 & 160 & 129 & 128 & 97 & 96 & 65 \\
\hline
\end{tabular}

Reproducción del grabado aparecido en la edición francesa de las "Obras" de Franklin (edición de Barbue-Dubourg, Paris, 1773). Yale University, Franklin Collection.

Esta copia aparece en: Claude-Anne López y Eugenia W. Herbert, The Private Franklin. The Man and His Family, New York, W.W. Norton \& Company Inc., 1975. 